\title{
Health or thinness? A content analysis of dietary behaviors promoted by Filipino food blogs
}

\author{
Danica P. Godinez ${ }^{1}$ and Jedess Miladel N. Salomon ${ }^{2 \star}$
}

\begin{abstract}
Food blogging communities, which have been steadily increasing over the years, are significant sources of dietary behaviors. However, studies revealed that some food blogs do not promote healthy dietary behaviors. This study generally aimed to determine the textual and visual content of the top five Filipino food blogs. Overall findings of the study imply that the bloggers delivered information that was associated with greater internalization of the thin ideal, appearance comparison, weight dissatisfaction, and drive for thinness among readers. The content also has negative/guilt inducing messages about food which could mean that the recipes posted may have problematic nutritional content especially that most of the bloggers were just "foodies", not nutrition experts. Although some entries were about health recipes, healthy eating choices, medical treatment and prevention, and exercising, which suggest that food blogs might promote healthy behaviors, this information has to be verified with experts. Filipino food blogs contain a variety of messages and information that may or may not promote healthy dietary behaviors. The results of this study could help provide awareness to those who get food and health-related information in the internet, specifically from the top Filipino food blogs.
\end{abstract}

Keywords: food blogs, dietary behaviors, health information

\section{INTRODUCTION}

In recent years, blogging has become one of the most popular media to share thoughts, feelings, opinions, and ideas. The popularity of blogs can be attributed to their capacity to give ordinary people a voice (Nilsson 2012). Because of their social nature, they have the ability to create networks for sharing ideas, trends, and information (Rettberg 2008).

In particular, food blogging typically represents a complex interweaving of "foodie" or gourmet interest in cooking, blog writing, and photography (Cox and Blake 2011). Food bloggers mostly use photos (Not Quite Nigella, 2009), write about travel and restaurants as well as publish food recipes (Robinson 2009). As food blogging becomes an occupation, food bloggers may form partnerships with

\footnotetext{
${ }^{1}$ Department of Development Communication, Visayas State University, Baybay City, Leyte, Philippines

${ }^{2}$ National Abaca Research Center, Visayas State University, Baybay City, Leyte, Philippines 
food companies or specific restaurants. Because of this, food blogs become modes of food advertising in which the level of the reader's trust on the blog may affect consumerism (Ho and Chein 2010). In fact, Hanifati (2015) found out that the perceived usefulness of a food blogger's recommendation has a significant effect on the consumer's intention to follow the recommendation. Moreover, most young adults search for information on nutrition and weight-loss strategies online (Banas 2008).

However, studies have shown that some food blogs do not promote healthy dietary practices. Schneider et al (2013) found that the recipes in six food blogs have met energy recommendations but were excessive in saturated fat and sodium. In addition, Lynch (2010) reported that some behaviors and attitudes associated with dietary restraint promoted by blogs have a number of serious health implications. These "healthy food blogs" do not actually encouraged healthy dietary practices as what the authors claimed.

Given this context, this pioneering study on Filipino food blogs could provide insight on the growing and complex sphere of new media. Today, society no longer relies on traditional sources of information. In the era of social media, people are directly engaged and become "the media" themselves (Thevenot 2007). Since anybody who has access to the Internet can post anything online, an analysis of the information that could potentially affect attitudes and behavior, especially those relating to health, should be done. Hence, this study aims to provide awareness on whether the information that Filipinos are getting from the top food blogs in the country could actually help them live healthier lifestyles or not. In addition, this study offers awareness for Filipinos to be more discerning of the information that they consume.

\section{METHODOLOGY}

This study is a content analysis of the five most popular Filipino food blogs. The sample consisted of five blogs written by Filipino women. These blogs were located in Feedspot, an RSS reader which stands for 'Really Simple Syndication' that lets you access updates to websites in a standardized, computer-readable format without actually visiting it. Aside from being a content reader, Feedspot also offers several services to consumers and marketers such as brand monitoring, blog promotion, and data curation, among others. At the time of the study, Feedspot has four million registered users across countries with over 2 million blog monthly visits (Feedspot nd).

The five blogs were chosen based on six selection criteria. First, blogs were required to be self-described as promoting food ethics, food styling and photography, restaurant reviews, recipes, and other terms associated with food sharing which are determined in the bloggers' profiles. Second, blogs should manifest social interaction by having discussion links and comment sections for feedback to meet the criteria of being a virtual community. Third, they should be active or maintained for at least one week prior to data collection to be defined as being updated. Fourth, they should have discussion of the bloggers' eating hobbies, food intake, and dietary behaviors and not simply recipes to know their food experiences and recommendations. Fifth, they should only have one author since 
blogs are defined as personal websites wherein people share their personal experiences. Lastly, the blogs should have social media accounts, particularly Facebook, where they share photos and blog links. Their popularity was gauged through the number of their Facebook likes and followers.

To guide the selection of samples for each blog, the entries should contain at least one of the following: 1) discussion of eating hobbies, food intake, and dietary behaviors of the bloggers which is basically about their food experiences; 2) content related to food, images of food, recipes; 3) content related to physical appearance andself-pictures; 4) content related to exercise and exercise images; 5) content related to weight; terms associated with being fat, thin, losing/gaining weight; and 6) discussion of health-related topics, personal health experiences, and medical information. Blog entries which did not fit at least one of the criteria were not chosen as entry samples. Based on the criteria, a total of 73 entries emerged for analysis.

The entries included in the study were those published from December 1 to January 26, 2018. According to Lynch (2010), two months (eight weeks) is a suitable time period for studying blogs considering the exceeding high number of entries as evidence of past similar research on blog communities. Additionally, this time frame was selected to include the content of the blogs posted during the holidays as Filipinos traditionally hold many celebrations with food as the central element. To determine the dietary behaviors promoted in the blogs, the entries were analyzed using Boepple and Thompson's (2014) four categories of codes (see Table 1). These codes were based on three similar internet-based content analyses (Waslykiw et al 2009; Labre 2005; Buis \& Carpenter 2009). To ensure the consistency and validity of the content analysis, intercoder reliability was established. In determining this, $10 \%$ of the total samples were coded independently by two (2) senior development communication students. Their degree of coding was determined and Cohen's kappa was computed. The rule of thumb says that if the value is above 0.70 , it means that the code book is highly reliable. The results of their coding showed that the codes for the visual content; treatment of textual information; readers' feedback; appearance variables; thin appearance variables; disordered food/nutrition variables; and health variables were reliable with Cohen's Kappa as all scores were above 0.70 . This study adhered to Boepple and Thompson's codes. There might be other variables that could be studied; however, these were not included as the researchers did not try to come up with new variables. 
Table1. Variables in coding the entries

\begin{tabular}{|c|c|}
\hline Codes For Entries & Description \\
\hline \multicolumn{2}{|l|}{ Appearance variables } \\
\hline Self-pictures & Pictures of self \\
\hline Self-objectifying phrase & Phrase which objectifies the body \\
\hline Exercise images & Images of selfexercising \\
\hline Beauty & $\begin{array}{l}\text { Content related to physical appearance or } \\
\text { attractiveness }\end{array}$ \\
\hline Style & $\begin{array}{l}\text { Content, unrelated to exercise, related to improvin } \\
\text { overall style }\end{array}$ \\
\hline Exercise clothes & Content related to exercise clothes \\
\hline \multicolumn{2}{|l|}{ Thin appearance ideal variables } \\
\hline Thin pose & Posed to appearthinner \\
\hline Losing weight/fat & $\begin{array}{l}\text { Explicit mention of losing fat or weight, or } \\
\text { previously lost fat or overweight }\end{array}$ \\
\hline Fat/overweight stigmatization & $\begin{array}{l}\text { Phrase which implies negativity about being fat o } \\
\text { overweight }\end{array}$ \\
\hline Thin praise & Phrase which implies positivity about beithlgin \\
\hline \multicolumn{2}{|l|}{ Disordered food/nutrition variables } \\
\hline $\begin{array}{l}\text { Negative/guiltinducing food } \\
\text { messages }\end{array}$ & Guilt or negative messages about food \\
\hline Food substitution & $\begin{array}{l}\text { Explicit substitution of foods for the purpose of } \\
\text { health or restraint }\end{array}$ \\
\hline Dieting & $\begin{array}{l}\text { Estimated consumption of less than } 1,200 \text { calorie } \\
\text { per day }\end{array}$ \\
\hline Dieting restraint & $\begin{array}{l}\text { Explicit restraint of a specific type of food for non } \\
\text { medical purposes }\end{array}$ \\
\hline \multicolumn{2}{|l|}{ Health variables } \\
\hline $\begin{array}{l}\text { Description personal health } \\
\text { experiences }\end{array}$ & Firsthand account of healthelated topic \\
\hline Provision medical info & $\begin{array}{l}\text { Impartial information related to medical condition } \\
\text { treatment, or prevention }\end{array}$ \\
\hline Discussion general health topics & Personal commentary on healttelated topic \\
\hline Mental health & Content related to mental health \\
\hline
\end{tabular}

\section{RESULTS AND DISCUSSION}

\section{The selected blogs}

Based on the set criteria, the blogs selected were the following: Ces Kitchen, Manila Spoon, The Peach Kitchen, The Tummy Train, and Yedylicious. All of the bloggers were females. Three live in the Philippines, while two are based in the 
Netherlands. All of them indicated their e-mail addresses.

In determining the blogs' number of subscribers, their Facebook followers were used as the proxy indicator since the number of subscribers was not indicated in the blogs themselves. Facebook accounts along with e-mail addresses can be used to subscribe to the blogs. It was found that Manila Spoon has the most number of followers $(160,279)$, followed by The Peach Kitchen $(33,927)$, The Tummy Train $(5,463)$, Yedylicious $(3,214)$, and Ces Kitchen $(1,656)$. Three of the five blogs (Manila Spoon, The Tummy Train and Yedylicious) posted 1-2 entries per week. One blog (Ces Kitchen) posted 2-3 entries per week, while the other (The Peach Kitchen) posted 3-4 times per week. From December 1, 2017 to January 26, 2018, a total of 73 blog entries were posted on the five blogs. The Peach Kitchen has a total of 29; Ces Kitchen has 17; The Tummy Train has 13; Manila Spoonand Yedylicious has a total of seven (7) each.

\section{Content of the images found in the blogs}

A total of 616 photographs were found in the five blog samples. Almost half of them were from The Tummy Train $(48.1 \%, n=296)$. The blog that has the second most number of photographs wasThe Peach Kitchen $(23.4 \%, n=144)$, less than oneeighth was from Manila Spoon $(11 \%, n=68)$, a little more than one-tenth was from Yedylicious $(10.95, n=67)$, and the rest were from Ces Kitchen $(6.7 \%, n=41)$. In total, 616 photographs published by the five food blogs were analyzed. Of the 616 visuals, more than half $(59.4 \%, n=366)$ were images of food while a little more than onefourth $(27.6 \%, n=170)$ were images of food cooking and preparation. On the other hand, only $5(0.8 \%)$ of the total samples were exercise images and there was no image related to beauty and health. Meanwhile, almost one-eight $(12.2 \%, n=75)$ of the remaining photographs were visuals still related to food like hotel and restaurant amenities, kitchen utensils, book recipes, and etc. (Table 2).

Table 2. Frequency distribution of visual content variables found in each blog entry

\begin{tabular}{|c|c|c|c|c|c|c|c|}
\hline \multirow[t]{2}{*}{ Blog } & \multicolumn{5}{|c|}{ Visual Content Variables } & Total & Percent \\
\hline & $\begin{array}{l}\text { Images } \\
\text { of food }\end{array}$ & $\begin{array}{l}\text { Images of } \\
\text { food } \\
\text { cooking \& } \\
\text { preparation }\end{array}$ & $\begin{array}{c}\text { Exercise } \\
\text { images }\end{array}$ & $\begin{array}{l}\text { Images } \\
\text { related to } \\
\text { beauty \& } \\
\text { health }\end{array}$ & Others & & \\
\hline Ces Kitchen & 26 & 5 & 0 & 0 & 10 & 41 & 6.70 \\
\hline $\begin{array}{l}\text { Manila } \\
\text { Spoon }\end{array}$ & 68 & 0 & 0 & 0 & 0 & 68 & 11.00 \\
\hline $\begin{array}{l}\text { The Peach } \\
\text { Kitchen }\end{array}$ & 99 & 2 & 5 & 0 & 38 & 144 & 23.40 \\
\hline $\begin{array}{l}\text { The Tummy } \\
\text { Train }\end{array}$ & 131 & 163 & 0 & 0 & 2 & 296 & 48.10 \\
\hline Yedylicious & 42 & 0 & 0 & 0 & 25 & 67 & 10.95 \\
\hline Total & 366 & 170 & 5 & 0 & 75 & 616 & 100.00 \\
\hline Percent & 59.40 & 27.60 & 0.80 & 0.00 & 12.20 & 100.00 & \\
\hline
\end{tabular}


This shows that the sample food blogs were mainly focused on the food that the bloggers ate and the recipes they cooked. It was found that the food images found in the blogs were colorful and styled in a way that emphasized appearance over nutritional value.

\section{Treatment of the textual information}

In terms of the treatment of the textual information, out of the 73 total blog entries, more than three-fourths $(78.1 \%)$ were features. More than one-eighth $(13.7 \%)$ were commentaries and more than one-sixteenth $(6.8 \%)$ were news features. The remaining entry (1.4\%) was on news article (Table 3 ).

Table 3. Format of textual information in the five sample blogs

\begin{tabular}{|c|c|c|c|c|c|}
\hline \multirow[t]{2}{*}{ Blog } & \multicolumn{4}{|c|}{ Textual Information } & Total \\
\hline & News & Feature & $\begin{array}{c}\text { News } \\
\text { Feature }\end{array}$ & Commentary & \\
\hline Ces Kitchen & 0 & 16 & 0 & 1 & 17 \\
\hline Manila Spoon & 0 & 7 & 0 & 0 & 7 \\
\hline The Peach Kitchen & 1 & 22 & 4 & 2 & 29 \\
\hline The Tummy Train & 0 & 9 & 0 & 4 & 13 \\
\hline Yedylicious & 0 & 3 & 1 & 3 & 7 \\
\hline Total & 1 & 57 & 5 & 10 & 73 \\
\hline Percent & 1.4 & 78.1 & 6.8 & 13.7 & 100 \\
\hline
\end{tabular}

The most featured content were the bloggers' food recipes. There was also a little commentary on the food they ate in a restaurant and some products they bought and used.

\section{Dietary behaviors promoted in the blogs}

Appearance variables. Appearance variables most likely emphasize overall physical appearance. The codes for this category were self-pictures, selfobjectifying phrases, exercise images, beauty, style, and exercise clothes. Table 4 shows that there were five (5) self-pictures displayed in the blog samples. More than half of it $(60 \%, \mathrm{n}=3)$ were the self-images of The Peach Kitchen blogger while the remaining two images were of the bloggers of The Tummy Train $(20 \%, n=1)$ and Ces Kitchen $(20 \%, n=1)$. There were no self-pictures found in the entries of both the Manila Spoon and Yedylicious.

The blogger of The Peach Kitchen, displayed pictures of herself exercising including written content related to the exercise clothes she was wearing. However, there was no self-objectifying phrase, content related to physical appearance and attractiveness, and content related to improving general style found in any of the 73 blog entries. 
Health or thinness? A content analysis of dietary behaviors

Table 4. Frequency distribution of appearance variables in entries

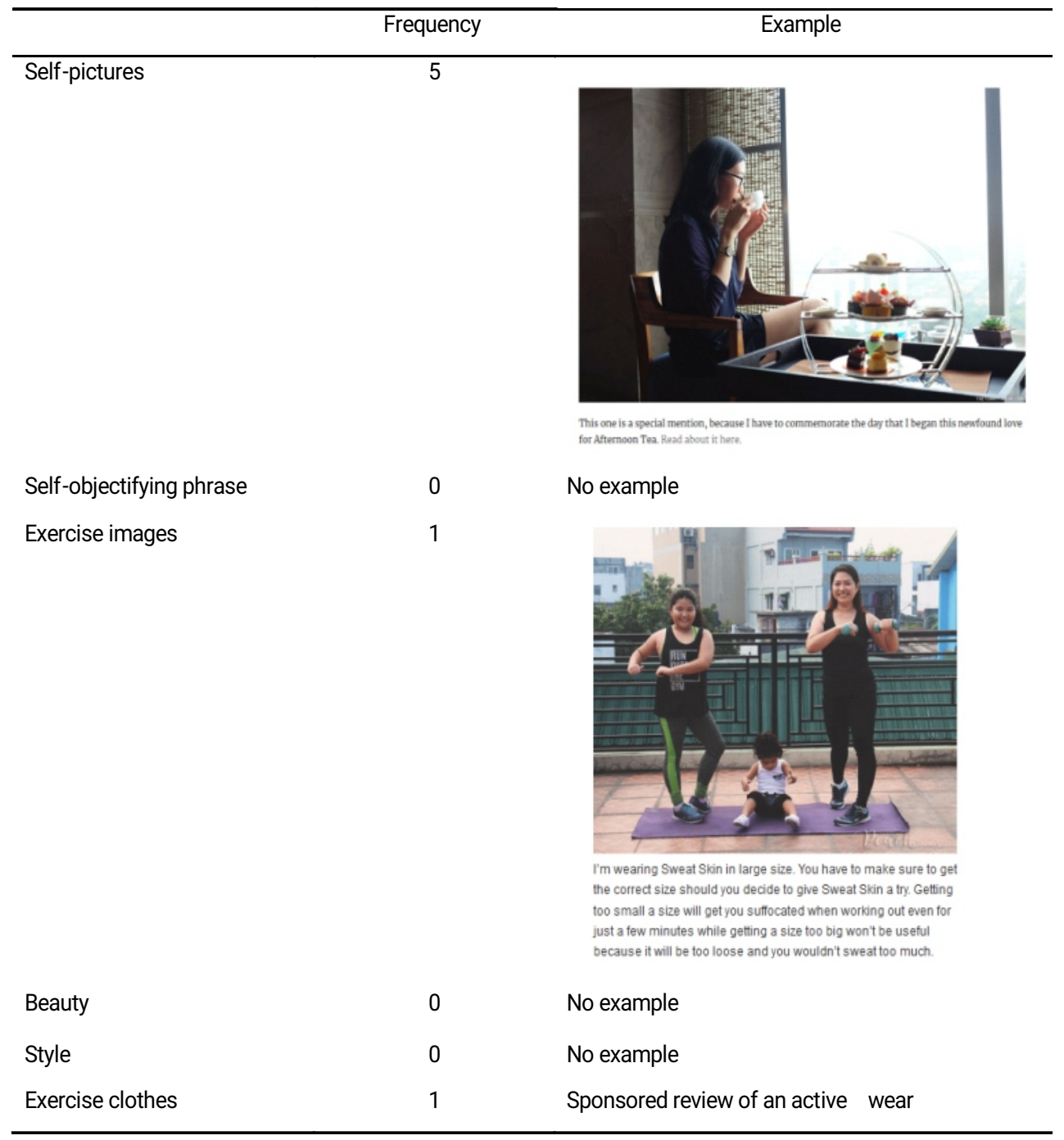

Thin appearance ideal variables. This category specifically exemplifies losing fat or weight. The codes were thin pose, losing fat/weight, fat/overweight stigmatization, and thin praise. The results of the thin appearance ideal variables revealed that two (2) bloggers mentioned losing fat or weight in their entries. One blogger was from The Peach Kitchen with exactly three-fourths $(75 \%, n=3)$ written content related to losing fat or weight and the remaining one-fourth $(25 \%, n=1)$ was mentioned by the blogger from Ces Kitchen. Additionally, The Peach Kitchen (50\%, $\mathrm{n}=1)$ and Ces Kitchen $(50 \%, \mathrm{n}=1)$ also mentioned some form of fat/overweight stigmatization in their entries (Table 5). 
Table 5. Frequency distribution of thin appearance ideal variables in entries

\begin{tabular}{lcl}
\hline & Frequency & \multicolumn{1}{c}{ Example } \\
\hline Thin pose & 0 & $\begin{array}{l}\text { No example } \\
\text { "I didn't stop working out because I'm } \\
\text { actually still 15 lbs away from my } \\
\text { weight goal." }\end{array}$ \\
$\begin{array}{lcl}\text { Fat/overweight } \\
\text { stigmatization }\end{array}$ & 4 & $\begin{array}{l}\text { "After gaining } 4 \mathrm{~kg} \text { in the span of a } \\
\text { month, I need to have a balance in life." } \\
\text { Thin praise }\end{array}$ \\
\hline
\end{tabular}

However, there was no phrase implying positivity about being thin. There was also no image of the bloggers posing in a way to make themselves look thinner or smaller.

Disordered food/nutrition variables. This category is about food and diet. The codes were food content, negative/guilt-inducing food messages, food substitution, dieting, and dieting restraint. The results of the disordered food/nutrition variables revealed that all of the bloggers featured content related to food in the entries. As shown in Table 6, almost all of the blog entries were related to food $(99 \%, n=72)$. Three (3) of the bloggers included some form of written negative/guilt-inducing message about food - one from The Peach Kitchen (20\%), one from Ces Kitchen (20\%) and three (3) from The Tummy Train (60\%).

Moreover, three (3) blogs mentioned about substitution of food for the purpose of health or restraint. Three-fourths of the food substitution content were from Ces Kitchen $(75 \%, n=6)$, one-eighth from Manila Spoon $(12.5 \%, n=1)$, and another oneeighth from The Peach Kitchen $(12.5 \%, \mathrm{n}=1)$. On the other hand, two blogs indicated some form of dietary restraint - one from Ces Kitchen $(50 \%, \mathrm{n}=1)$ and another from The Peach Kitchen $(50 \%, \mathrm{n}=1)$.

Table 6. Frequency distribution of disordered food/nutrition variables in entries

\begin{tabular}{lcl}
\hline Food content & Frequency & \multicolumn{1}{c}{ Example } \\
$\begin{array}{l}\text { Negative/guilt-inducing food } \\
\text { messages }\end{array}$ & 72 & $\begin{array}{l}\text { Blogger gave tips for introducing healthier } \\
\text { eating choices to the family }\end{array}$ \\
$\begin{array}{l}\text { Food substitution } \\
\text { "This is such an unhealthy pasta dish." }\end{array}$ & 8 & $\begin{array}{l}\text { "I believe it's already healthy but I'm 'healthy } \\
\text { frying' it even more by topping it on7 Grains } \\
\text { Organic Yellow Soybean Protein Pasta- a way } \\
\text { to eat pasta without the carbs." }\end{array}$ \\
Dieting & 0 & $\begin{array}{l}\text { No example } \\
\text { "Replacing a meal each day with a green } \\
\text { smoothie lowers overall calorie intake." }\end{array}$ \\
\hline
\end{tabular}

Health variables. For this category, the codes included were descriptions of personal health experiences, provision of medical information, discussion of general health topics, and mental health which emphasize fitness and overall wellbeing. The results indicated that three (3) blogs have discussed about personal 
health experiences. These were Ces Kitchen (33.3\%, $\mathrm{n}=1)$, Manila Spoon (33.3\%, $\mathrm{n}=1)$, and The Peach Kitchen $(33.3 \%, \mathrm{n}=1)$. The Peach Kitchen also has written content related to medical conditions, treatment, or prevention $(100 \%, n=3)$. Furthermore, almost all of the personal commentary on health-related topics were discussed by The Peach Kitchen $(85.7 \%, n=6)$, while the Manila Spoonhasdiscussed it once $(14.3 \%, n=1)$. No mental-health topic was discussed in any entry of the five blogs (Table 7).

Table 7. Frequency distribution of heath variables in entries

\begin{tabular}{|c|c|c|}
\hline & Frequency & Example \\
\hline $\begin{array}{l}\text { Description of personal } \\
\text { health experiences }\end{array}$ & 3 & $\begin{array}{l}\text { "The benefits of green smoothiesre many } \\
\text { and varied- they're easy to digest, keep you } \\
\text { hydrated, increase your energy, get skin } \\
\text { glowing, and more. l've tried and tested this } \\
\text { detox smoothie recipe last summer and it } \\
\text { actually worked." }\end{array}$ \\
\hline Provision of medical info & 3 & $\begin{array}{l}\text { "With a husband having hpertension, we are } \\
\text { trying to avoid eating red meat." }\end{array}$ \\
\hline $\begin{array}{l}\text { Discussion of general health } \\
\text { topics }\end{array}$ & 7 & $\begin{array}{l}\text { Blogger discussed about the varieties of rice } \\
\text { and their health benefits. }\end{array}$ \\
\hline Mental health & 0 & No example \\
\hline
\end{tabular}

One blogger has discussed about the benefits of drinking green smoothies. On the other hand, one blogger has textual content related to medical conditions, treatment, or prevention, and a personal commentary on a health-related topic. According to her, she and her family tried to avoid red meat to manage her husband's hypertension. She also discussed about rice varieties and their health benefits.

\section{IMPLICATIONS AND RECOMMENDATIONS}

With a total number of 204,539 Facebook followers, the top five Filipino food bloggers have a significant number of subscribers who get information on food and health from them. It is worth highlighting that these five bloggers were "laypeople" in terms of health and nutrition because none of them have any educational background on these subject matters, although one was a chef. Moreover, most of the content was features with a human interest angle, together with the bloggers' opinion and analysis.

These results indicate the following: 1) people tend to trust those whom they perceive as similar to them (Rutsaert et al 2013), and 2) the information available in these blogs could not be trusted in terms of good health and nutrition. Although this study only analyzed the blog content, the fact that these food bloggers have many Facebook followers indicate that many people chose to follow them and read their content. This is problematic because, according to Rutsaert et al (2013), when nonexpert information sources dominate a communication forum, there is an increased likelihood for inaccurate information to spread. To address this problem, food bloggers could work with nutritionists or dieticians to improve the nutritional content of their recipes. This is particularly important when they blog about food for 
health conscious individuals and weight-loss plans. They could also consult other sources with scientific information on health and nutrition and not just base their food and health recommendations on personal preferences and experiences.

Moreover, these bloggers post at least one blog per week and four entries at most. This shows how easy it is to provide and access information online. The proliferation of health information online, without any regulation in place, should make the public wary of the information and its sources. Since it is hard to monitor and regulate the huge number of blogs, the responsibility is placed on the readers to be discerning of the information they consume. If possible, they could verify the information they read with medical and nutrition experts.

To attract more readers and subscribers, the blogs used images that were found colorful and styled in a way that emphasized appearance over nutritional value. Some images were also of hotel and restaurant amenities and sponsored food ingredients. This implies that food blogs have become an advertising site for hotels, restaurants, and food products. This might influence readers and subscribers to prefer a specific type of ingredient regardless of its nutritional value. They might also be influenced to eat out in these restaurants, regardless of whether their food is healthy or not. Consequently, brands and companies have realized the influence of bloggers on a specific set of audience, hence, they have tapped into the capability of these bloggers to share and spread information about them and their products or services. Due to this, bloggers have now become opinion leaders (Mendoza, 2010).

The content analysis of textual information in the blogs has found that the top five Filipino bloggers delivered information associated with greater internalization of the thin ideal, appearance comparison, weight dissatisfaction, and drive for thinness among readers. The content also has negative/guilt inducing messages about food. Since the blogs were not developed in partnership with food and nutrition experts, their messages might trigger unhealthy eating and exercise habits. Moreover, the blogs have conveyed the idea that thin is beautiful and healthy, which is not true all of the time. Aside from that, some entries were about health recipes, healthy eating choices, medical treatments, disease prevention, and exercising which suggest that food blogs also promote healthy behaviors. However, readers and subscribers still need to validate this information with experts and doctors.

Although the top five Filipino food blogs attempt to share information on healthy food and behaviors, results of the study show that this might not always be the case. The Cultivation Theory (Gerbner 1973) posits that repeated exposure to messages affects a person's view of reality, and subsequently, his/her behavior. If readers and subscribers continually get food and health information from these blogs without consultation with experts, they might practice unhealthy behaviors. There are many studies on the effects of media on health behaviors, particularly relating to dietary disorders and body image. Examples are the studies of undergraduate women and adolescent girls by Harrison and Cantor (1997) and Thomsen et al (2002) which found that the extent of exposure to magazines that feature and glamorize the thin ideal is positively correlated with eating disorders, even controlling for the young woman's level of personal interest in fitness and dieting. Likewise, according to Murnen and colleagues (2007), thin ideal internalization was more strongly correlated with magazine reading and TV viewing, especially for children and adolescents under age eighteen. 
It is also important to note that this study has several limitations. First, it only focused on the top five Filipino food blogs namely: Ces Kitchen, Manila Spoon, The Peach Kitchen, The Tummy Train, and Yedylicious. With the increasing number of food blogs, researchers can also include other blogs, especially those with a significant number of subscribers. A comparative study of local and international food blogs could also yield interesting results. Also, "healthy living" blogs can be another community where health-related behaviors promoted in the Internet could be investigated.

Second, this only used content analysis to study the sample blogs. Further studies on food blogs could also involve nutrition and physical fitness experts who will evaluate the food nutrient content and health behaviors promoted in these blogs (heuristic evaluation). Further studies could also use quantitative and qualitative research techniques specifically designed for analyzing blogs (Webb and Wang 2013).

Additionally, since this study was only confined to the second prong of the Cultivation Theory which is the message system analysis, further research can include the two other prongs which are the institutional process analysis and the cultivation analysis. This would analyze the reasons why the bloggers produce the messages they do and how the blog content might affect the readers/subscribers. This can be done through online interviews. They can also use semiotics to explore the meanings that the blog content evokes in readers.

Lastly, though previous studies said that two months is the suitable period for studying blogs, future research can extend the timeframe to find out the textual and visual content of the food blogs through time.

\section{REFERENCES}

Banas J. 2008. A tailored approach to identifying and addressing college students' online health information literacy. American Journal of Health Education, 39(4), 228-236.

Boepple L and Thompson JK. 2014. A content analysis of healthy living blogs: Evidence of contentthematically consistent with dysfunctional eating attitudes and behaviors. International Journal of Eating Disorders, 47(4), 362-367.

Cox AM and Blake MK. 2011. Information and food blogging as serious leisure. In Aslib proceedings (Vol. 63, No. 2/3, pp. 204-220). Emerald Group Publishing Limited.

Gerbner G. 1973. Cultural indicators: The third voice. Communications technology and social policy, 11(1), 555-573.

Hanifati AN. 2015. The Impact of Food Blogger toward Consumer's Attitude and Behavior in Choosing Restaurant. International Journal of Humanities and ManagementSciences.2340-4044

Ho HY and Chien PHC. 2010. Influence of message trust in online word-of-mouth on consumer behavior-by the example of food blog. In Electronics and Information engineering (ICEIE), 2010 International Conference On (Vol. 1, pp.V1-395). IEEE.

Lynch M. 2010. Healthy habits or damaging diets: An exploratory study of a food bloggingcommunity. Ecology of food and nutrition, 49(4), 316-335. 


\section{Godinez and Salomon}

Mendoza M. 2010. I Blog, You Buy: How Bloggers are creating a New Generation of Product Endorsers. Journal of Digital Research \& Publishing, 7PM, 114-122.

Nilsson B. 2012. Politicians' blogs: Strategic self-presentations and identities. Identity, 12(3), 247-265.

Not Quite Nigella. 2009. Ten Things You Should Know about Food Bloggers. Retrieved at www.notquitenigella.com/2009/07/13/10-things-you-should know-about-foodbloggers/ on May 26, 2017.

Rettberg JW. 2008. Blogging (digital media and society).

Robinson L. 2009. The art of food blogging. Retrieved at www.timesonline.co.uk/ tol/life_and_style/food_and_drink/real_food/article5 5358.eceon May 26, 2017.

Rutsaert P, Regan A, Pieniak Z, McConnon A, Moss A, Wall P, et al. 2013. The Use of Social Media in Food Risk and Benefit Communication. Trends in Food Science \& Technology, 30, 84-91.

Schneider EP, McGovern EE, Lynch CL \& Brown LS. 2013. Do food blogs serve as a source of nutritionally balanced recipes? An analysis of 6 popular food blogs. Journal of nutrition education and behavior, 45(6), 696-700.

Thevenot G. 2007. Blogging as a social media. Tourism and hospitality research, 7(34), 287-289.

Webb LM and Wang Y. 2013. Techniques for analyzing blogs and micro-blogs. In N Sappleton (Ed.) Advancing Research Methods with New Technologies. 